\title{
Safety and Efficacy of Fimasartan in Patients with Arterial Hypertension (Safe-KanArb Study)
}

\section{An Open-Label Observational Study}

\author{
Jeong Bae Park $\cdot$ Ki-Chul Sung $\cdot$ Seok-Min Kang $\cdot$ \\ Eun Joo Cho
}

Published online: 24 January 2013

(c) The Author(s) 2013. This article is published with open access at Springerlink.com

\begin{abstract}
Background Angiotensin II receptor blockers (ARBs) play a key role in hypertension therapy. Recently, fimasartan, the ninth ARB, was developed, but its safety and efficacy have not been well established.

Objective The objective of this study was to determine whether age, sex, concomitant disease, and current antihypertensive medications affect the safety and efficacy of fimasartan in patients with arterial hypertension.

Methods This was a large-scale, open-label observational study to determine the safety and efficacy of fimasartan in patients with hypertension. Patients who were treated for more than 2 months with fimasartan (60 or $120 \mathrm{mg}$, once daily) were recruited, and the data were systematically
\end{abstract}

Electronic supplementary material The online version of this article (doi:10.1007/s40256-013-0004-9) contains supplementary material, which is available to authorized users.

\section{J. B. Park $(\bowtie)$}

Department of Medicine/Cardiology, Cheil General Hospital, Kwandong University College of Medicine, 1-19 Mukjung-dong, Jung-ku, Seoul 100-380, Korea

e-mail: mdparkjb@gmail.com

\section{K.-C. Sung}

Division of Cardiology, Department of Internal Medicine, Kangbuk Samsung Hospital, Sungkyunkwan University

School of Medicine, Seoul, Korea

\section{S.-M. Kang}

Cardiology Division, Severance Cardiovascular Hospital and Cardiovascular Research Institute, Yonsei University College of Medicine, Seoul, Korea

\section{E. J. Cho}

Division of Cardiology, St. Paul's Hospital,

Catholic University of Korea, Seoul, Korea collected using electronic case report forms. Written informed consent forms were obtained from all patients.

Results A total of 14,151 patients (50.7\% males; mean age $59 \pm 12$ years) were evaluated, of whom $37.9 \%$ were never treated with fimasartan, $53.5 \%$ were switched to fimasartan, and $8.5 \%$ had fimasartan added to their treatment. Overall, fimasartan reduced systolic blood pressure (SBP) from $145.4 \pm 18.1$ to $126.8 \pm 12.6 \mathrm{mmHg}$ and diastolic blood pressure (DBP) from $88.7 \pm 11.8$ to $79.0 \pm 8.7 \mathrm{mmHg}$ (all $p<0.001)$. The pulse rate decreased from $74.4 \pm 10.3$ to $71.9 \pm 9.2$ beats/min in comparison with before treatment $(p<0.001)$. The reductions were similar between sexes, age groups, and patients with and without co-morbidities, and were not dependent on prior or concomitant treatment with other antihypertensive drugs. Adverse events were reported in $3.31 \%$ (treatment-emergent) and $2.35 \%$ (drug-related) of patients; there were no dose differences for adverse events. The most frequent adverse events were dizziness $(1.55 \%)$ and headache $(0.52 \%)$; other adverse events were rare. The responder rate (DBP to $<90 \mathrm{mmHg}$ or a reduction of $\geq 10 \mathrm{mmHg}$ ) and the goal rate (combined SBP/DBP $<140 /$ $90 \mathrm{mmHg}$ ) were 85.0 and $75.6 \%$, respectively. Global drug compliance was rated as excellent, very good, good, and poor in $68.1,26.9,3.4$, and $1.7 \%$ of patients, respectively.

Conclusion The safety, efficacy, and compliance of fimasartan were found to be excellent in a large patient population that included patients potentially at higher risk for adverse events.

\section{Introduction}

Angiotensin II is the most important molecule in the reninangiotensin system. Angiotensin II increases heart contractions and sodium reabsorption and has harmful effects on 
organs and vessels due to vascular hypertrophy and vasoconstriction [1]. Restricting the effects of angiotensin II is not only effective in decreasing blood pressure (BP) but also has positive effects in preventing and improving heart failure, renal failure, stroke, and diabetic renal neuropathy [2-4]. Independent from the decrease in $\mathrm{BP}$, angiotensin antagonists decrease the incidence of cardiovascular events in a hypertensive and high-risk Asian population [5, 6]. For this reason, angiotensin II antagonists are listed as the initial medication prescribed for hypertensive patients in the European Society of Hypertension/European Society of Cardiology (ESH/ ESC) guidelines, and hypertension treatment guidelines of Japan [7, 8], and are also strongly recommended in some special circumstances according to the Joint National Committee (JNC) 7 hypertension guideline [9].

Since the approval of the first ARB, losartan, in 1995, more ARBs have been developed and are widely used as antihypertensive medications worldwide [10]. All the ARBs are generally similar in that they have the same goal of restricting angiotensin II, but each is distinct due to differences in potency, which vary according to pharmacokinetic profile. Some direct comparative studies have concluded that the recently developed ARBs lower BP better than the earlier ARBs, which may be due to the former's stronger degree of binding at the receptor level for a longer period of time [11, 12]. In addition, this difference is known to have additional effects, such as improving serum lipid levels and glucose metabolism [13] and lowering serum uric acid levels [14].

Fimasartan [(2-butyl-5-dimethylaminothiocarbonylmethyl-6-methyl-3-[[2'-(1H-tetrazol-5-yl) biphenyl-4-yl] methyl] pyrimidin- $4(3 \mathrm{H})$-one); molecular formula, $\mathrm{C}_{27} \mathrm{H}_{31} \mathrm{~N}_{7} \mathrm{OS}$; molecular weight 501.65; formally known as BR-A-657; Boryung Pharm. Co. Ltd, Seoul, Korea], the ninth ARB, was approved in September 2010 and was launched in March 2011 in Korea. This drug is a bioisosteric replacement of the imidazole part of losartan with pyrimidin-4(3H)-one that provided higher potency and stronger efficacy than losartan $[15,16]$ and exhibited a quick onset of antihypertensive effect during initial Phase II and III clinical trials [17]. The present study investigated drug safety and efficacy and patient compliance in hypertensive patients who were prescribed fimasartan for at least 2 months. In addition, the effects of the presence of concomitant disease and the application of other medications on the efficacy and side effects of the drug were also investigated.

\section{Methods}

\subsection{Design}

This was an open-label, observational study, in which 726 internal medicine doctors who specialize in primary care in
Korea participated. Among the patients prescribed fimasartan for more than 2 months, those who agreed to participate in the study were requested to systematically complete electronic case report forms. This research was approved by the Institutional Review Board of the Cheil General Hospital, Kwandong University College of Medicine, and informed consent forms were obtained from all patients.

\subsection{Patients}

There were no specific guidelines for the inclusion or exclusion of patients; however, to be eligible for inclusion in this study, the patient had to be 18 years or older and taking fimasartan under doctor's orders. Patients who were prescribed fimasartan since its release on 1 March 2011 in Korea were provided with informed written consent forms at each clinic, and the data were collected continuously from 25-30 patients who had been taking the medication at the approved dose of fimasartan 60 or $120 \mathrm{mg}$ for more than 2 months. Even patients who had not reached the 2-month duration of treatment were included in the study for the safety evaluation. The data were collected from a total of 14,571 patients, and statistical analyses were performed with the exclusion of data from the following: patients who did not have BP recorded before or after drug administration, patients who were given an uncommon dose of the drug ( 30 or $240 \mathrm{mg}$ ), and patients with unclear sources for their data. Thereafter, 14,151 patients $(50.7 \%$ males; mean age $59 \pm 12$ years) were analyzed, $37.9 \%$ of whom were never treated with fimasartan (the naïve group), $53.5 \%$ of whom were switched to fimasartan (the switched group), and $8.5 \%$ who had fimasartan added to their usual treatment (the add-on group). Of these patients, 10,543 patients were treated with $60 \mathrm{mg}$ of fimasartan and 3,608 patients with $120 \mathrm{mg}$ of fimasartan.

\subsection{Evaluation}

After obtaining a consent form, a questionnaire regarding patient risk factors, concomitant disease(s), and current medications was administered. The questionnaire was used to analyze the effects and the side effects of sex, age, concomitant disease, and risk factors. The definitions of various risk factors are as follows: males aged $\geq 55$ years and females aged $\geq 65$ years; smokers who have smoked in the past 30 days; obesity with a body mass index (BMI) $\geq 25 \mathrm{~kg} / \mathrm{m}^{2}$; abdominal obesity with a waist size greater than $90 \mathrm{~cm}$ for males and $80 \mathrm{~cm}$ for females; physical inactivity involving less than $2 \mathrm{~h}$ of exercise per week; diabetes with a fasting blood sugar (FBS) level $\geq 126 \mathrm{mg} /$ $\mathrm{dL}$ and/or being treated with medication or insulin; dyslipidemia with a low density lipoprotein (LDL)-cholesterol 
level $\geq 160 \mathrm{mg} / \mathrm{dL}$, a total (T)-cholesterol level $\geq 240 \mathrm{mg} /$ $\mathrm{dL}$, and a high density lipoprotein (HDL)-cholesterol level $<40 \mathrm{mg} / \mathrm{dL}$ for males and $<50 \mathrm{mg} / \mathrm{dL}$ for females or taking lipid-lowering medication; and a diagnosis of or presenting signs of sleep apnea as determined by a doctor.

All symptoms that followed drug administration were recorded, and the relevance to the drug was determined by the doctors. The efficacy of the drug was initially determined by the differences in the diastolic (DBP) and systolic (SBP) BPs before and after drug administration in the clinic. In addition, the responder rate was defined as a DBP $<90 \mathrm{mmHg}$ or decreased by $\geq 10 \mathrm{mmHg}$, and the goal rate was defined as a combined SBP/DBP $<140 / 90 \mathrm{mmHg}$ and $<130 / 80 \mathrm{mmHg}$ in patients with diabetes mellitus and renal disease, respectively [18]. All patients were asked about the number of drugs left when they visited the clinic and compliance was calculated by dividing the actual number of administrations by the planned number and was defined as excellent (100\%), very good (90-99\%), good $(80-89 \%)$, and poor $(<80 \%)$. For the quality assurance of the investigation, the coordination center of the Cheil General Hospital reviewed the entire database and verified approximately $39 \%$ of the data that was incomplete, questionable, or reported abnormal reactions.

\subsection{Statistics}

All statistical analyses were conducted using SAS version 9.2 (SAS Institute Inc., Cary, NC, USA). All participant data on demographic information, laboratory tests, ECG results, and medications for hypertension and other conditions are presented after calculating descriptive statistics for males and females. Abnormal reactions were coded and organized using the Medical Dictionary for Regulatory Activities (MedDRA) 10.0, and the frequencies and percentages of the participants with abnormal reactions in the different treatment groups are presented. All abnormal reactions were organized based on the presence of symptoms before and after taking fimasartan and the importance, severity, relevance, treatment, and termination of the reaction; abnormal reactions related to fimasartan, serious reactions, and reactions from incomplete participants were also noted.

To determine whether there was a difference in the incidence rate of an adverse event following administration of various doses of fimasartan, a Chi-squared $\left(\chi^{2}\right)$ or Fisher's exact test was used. In addition, a $\chi^{2}$ test and a logistic regression were used to identify correlations between the presence of adverse events and demographic information and medical history, a paired t-test was utilized to determine the difference between $\mathrm{BP}$ and pulse rate, a $t$ test was performed to analyze the difference between BP and pulse rate related to demographic information and medical history, and a multiple regression analysis was conducted to investigate relevance. A linear mixed model was analyzed to quantify the effects of fimasartan on the differences in BP among various groups, including a group that consisted of first-time hypertensive patients, a group that was originally taking antihypertensive medications to which fimasartan was added, and a group that ceased to take the original hypertension medication and was given fimasartan instead. To observe the effects of patient compliance (whether patients took the drug) on the degree of difference in BP, an analysis of covariance was conducted. Frequency and percentage, which are descriptive statistics, are presented according to the compliance rate, and a $\chi^{2}$ test was used to determine the relevance between compliance and demographic information and the presence of concomitant diseases.

\section{Results}

\subsection{Baseline Characteristics}

From May to August 2011, 14,151 Korean patients were recruited from all operating internal medicine clinics in Korea. A total of $50.7 \%$ of the patients were male, the average \pm SD age was $59.0 \pm 12.0$ years, and the average \pm SD BMI was $24.4 \pm 2.9 \mathrm{~kg} / \mathrm{m}^{2}$ (Table 1). The risk factor frequencies were $44.6 \%$ for old age ( $>60$ years), $9.9 \%$ for smoking, $37.6 \%$ for obesity, $66.4 \%$ for physical inactivity, and $18.8 \%$ for diabetes. Accompanying diseases determined by individual doctors were stroke (1.6\%) and ischemic heart disease (2.1\%; Table 1$)$. The participant population included $37.9 \%$ of new hypertension patients initially treated with fimasartan (the naïve group), $53.5 \%$ of patients who switched to fimasartan from other antihypertensive medications (the switched group), and $8.5 \%$ of patients who had fimasartan added to their regimen due to uncontrollable BP (the add-on group; Table 1). Of the concomitant antihypertensive medications, calcium channel blockers (CCBs) were the most common, about $25 \%$.

\subsection{Safety}

Out of the 14,151 patients, $450(3.31 \%)$ complained of adverse events after drug administration. Of the patients who complained, approximately $333(2.35 \%)$ patients were suspected of having a reaction related to the medication. The most frequent adverse events were dizziness $(1.55 \%)$ and headache $(0.52 \%)$. Other symptoms included fatigue, itching, abdominal pain, nausea, coughing, sleep disorder, tachycardia, acroparesthesia, chest discomfort, diarrhea, and back pain, but they occurred with very low 
Table 1 Baseline characteristics of patients a Patients who had never received any antihypertensive medication and received fimasartan

${ }^{b}$ Patients who were switched from other antihypertensive medication to fimasartan

${ }^{c}$ Patients who received add-on antihypertensive therapy with fimasartan

$* p$ value $\leq 0.01$ between men and women according to Pearson $\chi^{2}$ tests

$A C E I$ angiotensin converting enzyme inhibitor, $B P$ blood pressure, $C C B$ calcium channel blocker, $D B P$ diastolic BP, $S B P$ systolic BP

\begin{tabular}{|c|c|c|c|}
\hline Characteristic & Men and women $(n=14,151)$ & Men $(n=7,179)$ & $\begin{array}{l}\text { Women } \\
(n=6,972)\end{array}$ \\
\hline Age, y & $59.0 \pm 12.0$ & $56.7 \pm 11.9$ & $61.5 \pm 11.7 *$ \\
\hline Age $>60 \mathrm{y}, \%$ & 44.6 & 36.8 & $52.6^{*}$ \\
\hline Body weight, $\mathrm{kg}$ & $64.88 \pm 10.96$ & $70.72 \pm 9.97$ & $58.8 \pm 8.32 *$ \\
\hline Height, $\mathrm{cm}$ & $162.8 \pm 8.76$ & $169.07 \pm 6.38$ & $156.27 \pm 5.54 *$ \\
\hline Body mass index, $\mathrm{kg} / \mathrm{m}^{2}$ & $24.38 \pm 2.94$ & $24.68 \pm 2.75$ & $24.07 \pm 3.10^{*}$ \\
\hline Obesity, $\%$ & 37.6 & 41.5 & 33.5 \\
\hline Physical inactivity, \% & 66.4 & 65.0 & 67.9 \\
\hline Smoking, \% & $1,406(9.94)$ & $1,310(18.25)$ & $96(1.38)^{*}$ \\
\hline Alcohol use, $\%$ & $3,508(40.31)$ & $2,859(64.92)$ & $649(15.1)^{*}$ \\
\hline \multicolumn{4}{|l|}{ BP } \\
\hline $\mathrm{SBP}, \mathrm{mmHg}$ & $145.43 \pm 18.07$ & $146.2 \pm 17.62$ & $144.63 \pm 18.5 *$ \\
\hline $\mathrm{DBP}, \mathrm{mmHg}$ & $88.71 \pm 11.8$ & $89.83 \pm 11.86$ & $87.56 \pm 11.63 *$ \\
\hline Pulse rate, beats/min & $74.38 \pm 10.28$ & $74.76 \pm 10.55$ & $73.98 \pm 9.97 *$ \\
\hline \multicolumn{4}{|l|}{ Co-morbidity } \\
\hline Diabetes, \% & 18.8 & 19.4 & 18.2 \\
\hline Ischemic heart disease, $\%$ & 2.1 & 1.7 & 2.4 \\
\hline Stroke, $\%$ & 1.6 & 1.5 & 1.7 \\
\hline \multicolumn{4}{|l|}{ Concomitant medication } \\
\hline \multicolumn{4}{|l|}{ Antihypertensive drug } \\
\hline ACEI & $295(2.08)$ & $161(2.24)$ & $134(1.92)$ \\
\hline$\beta$-blocker & $809(5.72)$ & $394(5.49)$ & $415(5.95)$ \\
\hline $\mathrm{CCB}$ & $3,472(24.54)$ & $181(25.24)$ & $1,660(23.81)$ \\
\hline Diuretic & $1,320(9.33)$ & $615(8.57)$ & $705(10.11)^{*}$ \\
\hline$\alpha$-blocker & $28(0.2)$ & $19(0.26)$ & $9(0.13)$ \\
\hline Other antihypertensive drug & $388(2.74)$ & $198(2.76)$ & $190(2.73)$ \\
\hline Antiplatelet drug & 2,641 (18.66) & $1,308(18.22)$ & $1,333(19.12)$ \\
\hline Oral hypoglycemic drug & $2,371(16.75)$ & $1,225(17.06)$ & $1,146(16.44)$ \\
\hline Insulin & $131(0.93)$ & $67(0.93)$ & $64(0.92)$ \\
\hline Antidyslipidemic drug & $2,848(20.13)$ & $1,352(18.83)$ & $1,496(21.46)^{*}$ \\
\hline Anticoagulant & $279(1.97)$ & $110(1.53)$ & $169(2.42)$ \\
\hline \multicolumn{4}{|l|}{ Indication, \% } \\
\hline Naïve ${ }^{a}$ & 37.9 & 40.2 & 35.7 \\
\hline Change $^{\mathrm{b}}$ & 53.5 & 51.2 & 56.0 \\
\hline Add-on ${ }^{c}$ & 8.5 & 8.6 & 8.4 \\
\hline
\end{tabular}

frequency (Table 2). By indication, adverse effects were $3.42,2.81$, and $3.31 \%$ in the naïve patients, the switched patients, and the add-on group, respectively. There were 168 cases $(1.19 \%)$ in which the patients stopped taking the medication after the treatment had begun; in 135 of these cases $(0.95 \%$ of all of the patients) the discontinuation was related to the adverse effects of fimasartan. There was no significant difference between the 60-mg $(n=10,543)$ and 120 -mg ( $n=3,608$ ) groups, as the frequencies of adverse events were 3.19 and $3.02 \%$, respectively $(p=0.66)$. The adverse event profile was mostly not affected by concomitant medication except that co-administration of a $\beta$-blocker increased its frequency with an odds ratio of 1.757 (95\% CI 1.23-2.50). Even in occurrences of an adverse event, in most cases $(76.2 \%)$ the symptoms resolved without any special treatment, and no events that were immediately life threatening or could cause death occurred.

\subsection{Efficacy}

Treatment with fimasartan for more than 2 months decreased SBP by $18.7 \pm 18.3 \mathrm{mmHg}$ (from $145.4 \pm 18.1$ $\mathrm{mmHg}$ to $126.8 \pm 12.6 \mathrm{mmHg}$ ), and DBP decreased by $9.7 \pm 11.7 \mathrm{mmHg}$ (from $88.7 \pm 11.8 \mathrm{mmHg}$ to $79.0 \pm$ $8.7 \mathrm{mmHg}$ ) [all $p<0.001$ ] in all patients treated with 60 and $120 \mathrm{mg}$. The pulse rate decreased by $2.5 \pm 7.9$ beats/ $\min$ (from $74.4 \pm 10.3$ beats $/ \mathrm{min}$ to $71.9 \pm 9.2$ beats $/ \mathrm{min}$ ) [ $p<0.001$; Table 3]. In the naïve group, SBP decreased by 
Table 2 Adverse effects in patients taking fimasartan

\begin{tabular}{|c|c|c|c|}
\hline Category & Symptoms & No. & $(\%)$ \\
\hline \multirow[t]{8}{*}{ Skin and appendage disorders } & Skin rash & 2 & $(0.38)$ \\
\hline & Facial flushing & 2 & $(0.38)$ \\
\hline & Itching & 18 & $(3.39)$ \\
\hline & Acne & 1 & $(0.19)$ \\
\hline & Chloasma & 1 & $(0.19)$ \\
\hline & Bruise & 1 & $(0.19)$ \\
\hline & Toenail hemorrhage & 1 & $(0.19)$ \\
\hline & Cold sweating & 1 & $(0.19)$ \\
\hline \multirow{4}{*}{$\begin{array}{l}\text { Musculoskeletal system } \\
\text { disorders }\end{array}$} & Stiff neck & 2 & $(0.38)$ \\
\hline & $\begin{array}{l}\text { Temporomandibular } \\
\text { pain }\end{array}$ & 1 & $(0.19)$ \\
\hline & Back pain & 4 & $(0.75)$ \\
\hline & Chest discomfort & 5 & $(0.94)$ \\
\hline \multirow{6}{*}{$\begin{array}{l}\text { Central and peripheral } \\
\text { nervous system disorders }\end{array}$} & Headache & 85 & $(16.01)$ \\
\hline & Unconsciousness & 1 & $(0.19)$ \\
\hline & $\begin{array}{l}\text { Menstrual } \\
\text { irregularity }\end{array}$ & 1 & $(0.19)$ \\
\hline & Dizziness & 252 & $(47.46)$ \\
\hline & Acroparesthesia & 5 & $(0.94)$ \\
\hline & Bitter taste & 1 & $(0.19)$ \\
\hline \multirow[t]{3}{*}{ Vision disorders } & Visual disturbance & 1 & $(0.19)$ \\
\hline & Blurred vision & 1 & $(0.19)$ \\
\hline & Phlebitis & 1 & $(0.19)$ \\
\hline $\begin{array}{l}\text { Hearing and vestibular } \\
\text { disorders }\end{array}$ & Tinnitus & 1 & $(0.19)$ \\
\hline \multirow[t]{3}{*}{ Psychiatric disorders } & Sleep disorder & 8 & $(1.51)$ \\
\hline & Photophobia & 1 & $(0.19)$ \\
\hline & Delirium & 1 & $(0.19)$ \\
\hline \multirow{11}{*}{$\begin{array}{l}\text { Gastrointestinal system } \\
\text { disorders }\end{array}$} & Periodontal disease & 1 & $(0.19)$ \\
\hline & Stomatitis & 1 & $(0.19)$ \\
\hline & Diarrhea & 3 & $(0.56)$ \\
\hline & Constipation & 3 & $(0.56)$ \\
\hline & Abdominal pain & 16 & $(3.01)$ \\
\hline & Nausea & 14 & $(2.64)$ \\
\hline & Vomiting & 2 & $(0.38)$ \\
\hline & Heartburn & 3 & $(0.56)$ \\
\hline & Dyspepsia & 2 & $(0.38)$ \\
\hline & Epigastric soreness & 2 & $(0.38)$ \\
\hline & Gas distension & 1 & $(0.19)$ \\
\hline $\begin{array}{l}\text { Metabolic and nutritional } \\
\text { disorders }\end{array}$ & Hyperlipidemia & 3 & $(0.56)$ \\
\hline \multirow{2}{*}{$\begin{array}{l}\text { Cardiovascular disorders, } \\
\text { general }\end{array}$} & Low blood pressure & 7 & $(1.32)$ \\
\hline & Hypertension & 3 & $(0.56)$ \\
\hline \multirow{2}{*}{$\begin{array}{l}\text { Heart rate and rhythm } \\
\text { disorders }\end{array}$} & Angina & 1 & $(0.19)$ \\
\hline & Tachycardia & 5 & $(0.94)$ \\
\hline \multirow[t]{2}{*}{ Vascular disorders } & Palpitation & 5 & $(0.94)$ \\
\hline & Varicose vein & 1 & $(0.19)$ \\
\hline
\end{tabular}

Table 2 continued

\begin{tabular}{llrl}
\hline Category & Symptoms & No. & $(\%)$ \\
\hline Respiratory disorders & Asthma & 1 & $(0.19)$ \\
& Dyspnea & 3 & $(0.56)$ \\
& Sputum & 1 & $(0.19)$ \\
& Shortness of breath & 4 & $(0.75)$ \\
Reproductive disorders & Coughing & 14 & $(2.64)$ \\
Body as a whole - general & Erectile insufficiency & 2 & $(0.38)$ \\
disorders & Fatigue & 18 & $(3.39)$ \\
& Anorexia & 2 & $(0.38)$ \\
& Weight loss & 2 & $(0.38)$ \\
& Dry mouth & 1 & $(0.19)$ \\
& Facial edema & 3 & $(0.56)$ \\
& Ankle edema & 1 & $(0.19)$ \\
& Others & 8 & $(1.51)$ \\
\hline
\end{tabular}

$26.4 \pm 17.3 \mathrm{mmHg}$ (from $153.9 \pm 15.5 \mathrm{mmHg}$ to $127.4 \pm$ $12.4 \mathrm{mmHg}$ ), and DBP decreased by $13.9 \pm 11.6 \mathrm{mmHg}$ (from $93.8 \pm 11.1 \mathrm{mmHg}$ to $79.9 \pm 8.7 \mathrm{mmHg}$ ). The pulse rate was reduced by $3.2 \pm 8.09$ beats/min (from $75.5 \pm 10.6$ beats $/ \mathrm{min}$ to $72.2 \pm 9.4$ beats $/ \mathrm{min}$ ) [all $p<$ 0.001]. Furthermore, this group had a larger range of reduction compared with the add-on and the switched groups. The reduction in each group is depicted in Fig. 1.

Administration of $120 \mathrm{mg}$ of fimasartan decreased SBP and DBP by $20.1 \pm 19.1$ and $10.2 \pm 12.4 \mathrm{mmHg}$, respectively, which were significantly greater reductions than the $18.2 \pm 18.0 \mathrm{mmHg} \quad(p<0.001)$ and $9.6 \pm 11.4 \mathrm{mmHg}$ ( $p=0.01$ ) decreases observed with the 60-mg dose. The pulse rate decreased more with the $120-\mathrm{mg}$ dose than with the $60-\mathrm{mg}$ dose ( $2.9 \pm 8.5$ vs. $2.4 \pm 7.6$ beats $/ \mathrm{min}, p<0.001$; Table 4$)$.

There were no significant differences when multiple regression analyses were performed on the changes in $\mathrm{BP}$ and the pulse rate based on demographic information and medical history. However, as age increased, there were larger changes in SBP and DBP (Table 5).

\subsection{Responder Rate and Goal Rate}

The responder rate (DBP to $<90 \mathrm{mmHg}$ or a reduction of $\geq 10 \mathrm{mmHg}$ ) and the goal rate (combined SBP/DBP $<140 /$ $90 \mathrm{mmHg}$ ) were, respectively, $85.0 \%$ and $75.6 \%$ in the naïve patient group, $87.9 \%$ and $74.5 \%$ in the add-on group, and $90.1 \%$ and $79.7 \%$ in the switched group. The $60-\mathrm{mg}$ dose had better responder and goal rates than the $120-\mathrm{mg}$ dose for the naïve patient group and better goal rates for the add-on group and the switched group (all $p<0.001$; Table 6). Even after revising for age and sex, SBP and DBP decreased when fimasartan was added ( $\beta-$ 
Table 3 Blood pressure response before and after more than 2 months' treatment with fimasartan $(60$ and $120 \mathrm{mg})$ in all patients

\begin{tabular}{lccc}
\hline Patients & Before treatment & After treatment & Difference \\
\hline Men and women & & & \\
SBP, mmHg & $145.43 \pm 18.07$ & $126.77 \pm 12.61$ & $-18.65 \pm 18.29^{*}$ \\
DBP, mmHg & $88.71 \pm 11.80$ & $78.98 \pm 8.66$ & $-9.73 \pm 11.67^{*}$ \\
Pulse rate, beats/min & $74.38 \pm 10.28$ & $71.88 \pm 9.19$ & $-2.5 \pm 7.85$ \\
Men & & & \\
SBP, mmHg & $146.20 \pm 17.62$ & $127.49 \pm 12.63$ & $-18.71 \pm 17.62^{*}$ \\
DBP, mmHg & $89.83 \pm 11.86$ & $79.78 \pm 8.83$ & $-10.05 \pm 11.67^{*}$ \\
Pulse rate, beats/min & $74.76 \pm 10.55$ & $72.21 \pm 9.40$ & $-2.55 \pm 8.07^{*}$ \\
Women & & & \\
SBP, mmHg & $144.63 \pm 18.50$ & $126.03 \pm 12.55$ & $-18.60 \pm 18.96^{*}$ \\
DBP, mmHg & $87.56 \pm 11.63$ & $78.16 \pm 8.41$ & $-9.39 \pm 11.65^{*}$ \\
Pulse rate, beats/min & $73.98 \pm 9.97$ & $71.54 \pm 8.95$ & $-2.45 \pm 7.61^{*}$ \\
\hline
\end{tabular}

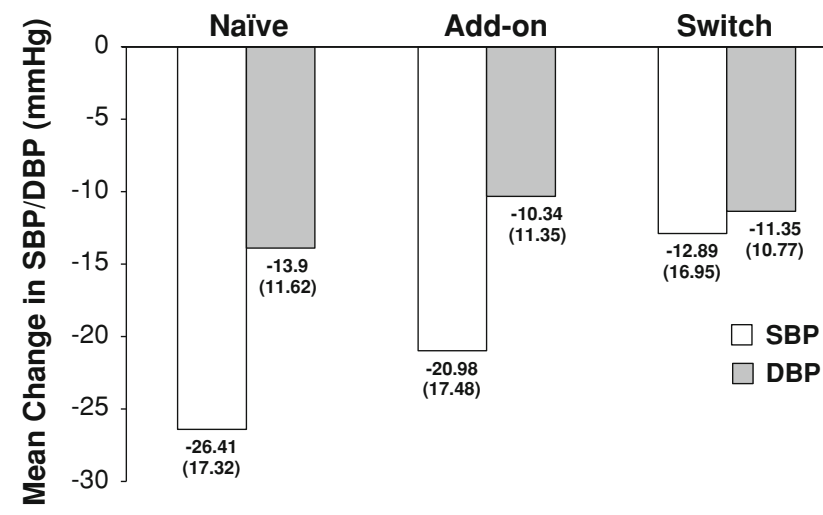

Fig. 1 Changes in systolic (SBP) and diastolic (DBP) blood pressure in all patients treated with 60 and $120 \mathrm{mg}$ of fimasartan

21.7/-10.3; all $p<0.001$ ), and the patients who switched to fimasartan also exhibited decreases in SBP and DBP values $(\beta-12.4 /-6.3$, all $p<0.001)$.

\subsection{Compliance}

The compliance of the patients with the drug was calculated by dividing the actual number used or consumed by the planned number of administrations. Overall, drug compliance was very high; excellent compliance was at $68.1 \%$, very good compliance was at $26.9 \%$, good compliance was at $3.4 \%$, and poor compliance was at $1.7 \%$ (Table 7). A higher compliance rate resulted in larger effects on DBP and SBP (Table 8).

\section{Discussion}

This study was conducted approximately 2-3 months after the launch of fimasartan, the ninth ARB to be developed, to investigate its safety and efficacy in a realistic clinical setting. Although there was no direct comparison between
Table 4 Dose-dependent changes in blood pressure before and after treatment with fimasartan

\begin{tabular}{llll}
\hline Patients & Fimasartan & Fimasartan & $P$ value \\
& $60 \mathrm{mg}$ & $120 \mathrm{mg}$ & \\
\end{tabular}

Men and women

$\Delta$ SBP, mmHg $\quad-18.16 \pm 17.97 \quad-20.10 \pm 19.14 \quad<.0001$

$\triangle \mathrm{DBP}, \mathrm{mmHg} \quad-9.57 \pm 11.40 \quad-10.17 \pm 12.41 \quad 0.0103$

$\Delta$ Pulse rate, beats $/ \mathrm{min} \quad-2.36 \pm 7.62 \quad-2.91 \pm 8.47 \quad 0.0005$ Men

$\begin{array}{lccc}\Delta \mathrm{SBP}, \mathrm{mmHg} & -18.23 \pm 17.37 & -19.93 \pm 18.22 & 0.0003 \\ \Delta \mathrm{DBP}, \mathrm{mmHg} & -10.00 \pm 11.45 & -10.17 \pm 12.22 & 0.5796 \\ \Delta \text { Pulse rate, beats/min } & -2.37 \pm 7.78 & -3.00 \pm 8.76 & 0.0050\end{array}$

Women

\begin{tabular}{lccc}
$\Delta \mathrm{SBP}, \mathrm{mmHg}$ & $-18.09 \pm 18.53$ & $-20.31 \pm 20.23$ & $<.0001$ \\
$\Delta \mathrm{DBP}, \mathrm{mmHg}$ & $-9.16 \pm 11.32$ & $-10.17 \pm 12.65$ & 0.0039 \\
$\Delta$ Pulse rate, beats/min & $-2.34 \pm 7.45$ & $-2.79 \pm 8.11$ & 0.0456 \\
\hline
\end{tabular}

$\triangle$ indicates change, $D B P$ diastolic blood pressure, SBP systolic blood pressure, $* p$-value between 60 versus $120 \mathrm{mg}$

conventional ARBs and fimasartan, the efficacy of fimasartan at a dose of either 60 or $120 \mathrm{mg}$ once daily appeared to be excellent, and side effects were minimal. Furthermore, fimasartan had a powerful effect in decreasing BP, and the efficacy and adverse event profile were unaffected by age, sex, or the presence of diabetes or concomitant disease, such as heart and brain diseases, and in particular not by concomitant medication.

\subsection{Safety and Tolerability}

ARBs are widely preferred over other antihypertensive medications because of their placebo-like tolerability [19]. As such, this study exhibited a rate of adverse events related to the medication of approximately $2.35 \%$, and no life-threatening adverse reactions were noted. This low adverse event rate improves treatment tolerability; the administration of fimasartan had a $0.95 \%$ early 
Table 5 Multiple regression analysis on blood pressure (BP) reductions, using baseline BP, age, sex, and other co-morbidities

\begin{tabular}{|c|c|c|c|c|c|c|c|c|c|}
\hline \multirow[t]{2}{*}{ Variable } & \multicolumn{3}{|l|}{$\Delta \mathrm{SBP}$} & \multicolumn{3}{|l|}{$\triangle \mathrm{DBP}$} & \multicolumn{3}{|l|}{$\Delta \mathrm{PR}$} \\
\hline & $\beta$ & $\operatorname{SE}(\beta)$ & $P$ value & $\beta$ & $\mathrm{SE}(\beta)$ & $P$ value & $\beta$ & $\operatorname{SE}(\beta)$ & $P$ value \\
\hline Women & -0.42 & 1.67 & 0.801 & 1.27 & 1.02 & 0.211 & 1.49 & 0.64 & 0.021 \\
\hline Age & 0.18 & 0.07 & 0.007 & 0.12 & 0.04 & 0.004 & 0.00 & 0.03 & 0.972 \\
\hline History of cardiovascular disease & 4.57 & 2.38 & 0.055 & 2.42 & 1.45 & 0.096 & 3.06 & 0.92 & 0.001 \\
\hline Smoking & 2.05 & 2.06 & 0.321 & 2.10 & 1.26 & 0.095 & 0.98 & 0.79 & 0.215 \\
\hline High BMI & -2.19 & 1.60 & 0.172 & -0.94 & 0.98 & 0.335 & -0.95 & 0.62 & 0.121 \\
\hline Abdominal obesity & -0.62 & 1.64 & 0.703 & -0.25 & 1.00 & 0.801 & 0.61 & 0.63 & 0.335 \\
\hline Physical inactivity & 0.56 & 1.48 & 0.706 & -0.04 & 0.90 & 0.962 & 0.32 & 0.57 & 0.570 \\
\hline Diabetes & 0.10 & 2.24 & 0.965 & 0.23 & 1.36 & 0.865 & -1.91 & 0.86 & 0.027 \\
\hline Dyslipidemia & 1.61 & 1.54 & 0.297 & 1.06 & 0.94 & 0.260 & -1.12 & 0.59 & 0.059 \\
\hline Family history of hypertension & 1.64 & 1.76 & 0.351 & 0.17 & 1.07 & 0.874 & -0.46 & 0.68 & 0.498 \\
\hline Renal dysfunction & -2.76 & 2.84 & 0.331 & -0.61 & 1.73 & 0.725 & -1.46 & 1.09 & 0.181 \\
\hline Sleep apnea & 0.20 & 2.10 & 0.925 & -1.20 & 1.28 & 0.352 & -0.33 & 0.81 & 0.683 \\
\hline $\mathrm{R}^{2}$ & \multicolumn{3}{|c|}{0.02} & \multicolumn{3}{|c|}{0.02} & \multicolumn{3}{|c|}{0.017} \\
\hline
\end{tabular}

$\Delta$ indicates change, $B M I$ body mass index, $S E$ standard error

Table 6 Responder and goal rates with fimasartan 60 and $120 \mathrm{mg}$

\begin{tabular}{|c|c|c|c|}
\hline Variable & $60 \mathrm{mg}$ & $120 \mathrm{mg}$ & Both \\
\hline \multicolumn{4}{|c|}{ Responder rate } \\
\hline Naïve $^{a}$ & 86.1 & $81.2^{*}$ & 85.0 \\
\hline Add-on ${ }^{b}$ & 88.3 & 86.9 & 87.9 \\
\hline Switch $^{\mathrm{c}}$ & 90.9 & 87.7 & 90.1 \\
\hline \multicolumn{4}{|l|}{ Goal rate } \\
\hline Naïve $^{a}$ & 77.7 & $68.4^{*}$ & 75.6 \\
\hline Add-on ${ }^{b}$ & 77.9 & $65.3^{*}$ & 74.5 \\
\hline Switch $^{\mathrm{c}}$ & 81.7 & $74.4^{*}$ & 79.7 \\
\hline
\end{tabular}

Data are given as percent

${ }^{\text {a }}$ Patients who had never received any antihypertensive medication and received fimasartan

${ }^{b}$ Patients who were switched from other antihypertensive medication to fimasartan

c Patients who received add-on antihypertensive therapy with fimasartan

$* p<0.001$ versus $60 \mathrm{mg}$ according to the $\chi^{2}$ test

Table 7 Overall drug compliance

\begin{tabular}{lrll}
\hline Compliance rate & Men & Women & Men and women \\
\hline Excellent $(100 \%)$ & 67.0 & 69.2 & 68.1 \\
Very good $(90 \sim 99 \%)$ & 27.5 & 26.2 & 26.9 \\
Good $(80 \sim 89 \%)$ & 3.8 & 3.0 & 3.4 \\
Poor $(<80 \%)$ & 1.7 & 1.7 & 1.7 \\
\hline
\end{tabular}

termination rate in the study. Although this study is an observational study, considering that the discontinuation rates are in the range of 2.5-9.3\% for other hypertension medications [20] and are $2.3 \%, 2.4 \%$, and $3.3 \%$ for the
Table 8 Blood pressure changes according to compliance ${ }^{\mathrm{a}}$

\begin{tabular}{|c|c|c|c|c|c|c|}
\hline \multirow{2}{*}{$\begin{array}{l}\text { Compliance } \\
\text { rate }\end{array}$} & \multicolumn{3}{|l|}{$\Delta \mathrm{SBP}$} & \multicolumn{3}{|c|}{$\Delta \mathrm{DBP}$} \\
\hline & $\beta$ & $\operatorname{SE}(\beta)$ & $P$ value & $\beta$ & $\operatorname{SE}(\beta)$ & $P$ value \\
\hline $\begin{array}{l}\text { Excellent } \\
(100 \%)\end{array}$ & -10.8 & 0.77 & $<0.001$ & -5.33 & 0.52 & $<0.001$ \\
\hline $\begin{array}{l}\text { Very good } \\
\quad(90 \sim 99 \%)\end{array}$ & -10.9 & 0.79 & $<0.001$ & -5.29 & 0.53 & $<0.001$ \\
\hline $\begin{array}{l}\text { Good } \\
\quad(80 \sim 89 \%)\end{array}$ & -6.60 & 0.93 & $<0.001$ & -3.78 & 0.63 & $<0.001$ \\
\hline \multicolumn{7}{|l|}{$\begin{array}{l}\text { Poor } \\
\qquad(<80 \%)\end{array}$} \\
\hline $\mathrm{R}^{2}$ & & 0.58 & & & 0.53 & \\
\hline
\end{tabular}

${ }^{a}$ Analysis of covariance, based on poor compliance

widely used ARBs losartan, candesartan, and irbesartan, respectively [21, 22], the $0.95 \%$ rate for fimasartan is markedly lower. When compared with the discontinuation rate of 1.1-2.1\% for azilsartan medoxomil and 1.1-6.1\% for valsartan $(320 \mathrm{mg})$ [23], the rate for fimasartan is still very low. The most common side effect related to fimasartan in this study was dizziness, which can be attributed to the powerful and rapid decrease in BP; there was no difference in the incidence of dizziness between the $60-\mathrm{mg}$ and 120-mg groups. Dizziness occurred more often in the ARB group than in the placebo group, and episodes of documented hypotension did not occur as frequently as expected. Future research is needed to ascertain the efficacy and tolerability of low-dose fimasartan (a half-dose of $60 \mathrm{mg}$, the smallest dose currently available).

In this study, dizziness occurred at a rate of $3.48 \%$ for patients under 60 years of age and $2.78 \%$ for patients over 60 years of age, which is thought to imply that the 
medication is more effective in lowering the $\mathrm{BP}$ for patients under 60 years of age. However, there was no difference in the frequency of dizziness in patient groups above or below 75 years of age $(p=0.553$, data not shown). Therefore, the administration of the medication is safer in an older population, regardless of the dosage. As this is an important issue, it certainly requires further investigation.

In a previous study, the frequency of cough related to an ARB was no higher than the frequency in the placebo group, but it was significantly lower compared with the angiotensin-converting enzyme inhibitor (ACEI) group [19]. This study had a low frequency of cough $(2.9 \%)$ that did not cause discontinuation of the medication. The frequency of angioedema also occurred less frequently at 0.1-0.2 \% when taking an ARB compared with an ACEI $[24,25]$. Therefore, for a patient who experiences angioedema due to ACEI treatment, an ARB is recommended as an alternative medication [26].

\subsection{Efficacy}

For hypertensive patients with little fluctuation in the actual degree of $\mathrm{BP}$ change according to different ARB formulations, the average SBP and DBP values decrease approximately 10 and $5 \mathrm{mmHg}$, respectively, after administration of the recommended daily dose of an ARB $[27,28]$. Aside from the powerful antihypertensive property of fimasartan, this can also be attributed to the fact that the participants in this study were relatively young, lowrisk hypertension patients with no complications such as stroke or diabetes. It can also be attributed to the fact that this study targeted hypertensive patients who visited primary-care clinics. We found that there was a large decrease in SBP/DBP in the naïve group relative to the other two groups. It is difficult to say whether this is unique to this drug or whether this depends on the patient population in this observational study. One possible explanation for those differences is that BP before fimasartan treatment in the naïve group was higher than that in the other two groups (about $15 \mathrm{mmHg}$ in the switch group, and about $4.4 \mathrm{mmHg}$ in the add-on group). This is because higher BP at baseline usually shows a larger reduction.

This study was conducted using two drug doses, 60 and $120 \mathrm{mg}$; the higher dose group showed a slightly greater decrease in SBP of $1.9 \mathrm{mmHg}$. As in most clinical trials evaluating ARBs, this study did not result in greatly different changes in BP due to the dose of the medication. In fact, a study involving the most recently developed ARB, azilsartan, showed no difference in BP over a wide dose range of $5-80 \mathrm{mg}$, nor did the capacity to control BP improve [29]. Another interesting fact observed in this study was a significant decrease in the pulse rate after administration of fimasartan, which can lead to the possibility of fimasartan blocking the sympathetic nervous system (SNS), similar to the effects of blocking the reninangiotensin-aldosterone system (RAAS) and the SNS, as observed with eprosartan [30]. Angiotensin (Ang) II stimulates the SNS, and the SNS stimulates the secretion of renin and Ang II. Hence, inhibition of Ang II activity might decrease the activity of the SNS. This probably explains a decrease in pulse rate with fimasartan. This hypothesis needs to be supported with experimental studies and comparative clinical trials in the future.

\subsection{Responder and Goal Rates}

A responder was defined as having a DBP $<90 \mathrm{mmHg}$ or a DBP reduction of $\geq 10 \mathrm{mmHg}$; the responder rate was very high, as it nearly reached $85-90 \%$. It is possible that the 120 -mg dosage group had a lower responder rate than the 60-mg dosage group because of the difference in BP at the beginning of treatment. The baseline SBP of the patients receiving $120 \mathrm{mg}$ was almost $5 \mathrm{mmHg}$ higher but the difference in BP between the 60 and $120 \mathrm{mg}$ doses was only $2 \mathrm{mmHg}$ after treatment. The goal rate of having a combined SBP and DBP below 140/90 $\mathrm{mmHg}$ was excellent at approximately $76.6 \%$, similar to the responder rate. Particularly among patients whose BPs could not be controlled with conventional antihypertensive medications, those who switched to or added fimasartan displayed significant effects of fimasartan and high rates of reaching the goal BP.

\subsection{Compliance}

ARB medication has a relatively low occurrence of adverse events compared to ACEIs. This low adverse event rate results in increased compliance among hypertensive patients, which, in turn, makes controlling their BP more feasible. For this reason, ultimately, ARB medication is thought to contribute to lowering the incidence and mortality rates associated with cardiovascular diseases. In this study, patient compliance was calculated by dividing the actual number used or consumed by the planned number of administrations. Approximately $95 \%$ of the entire patient population accounted for the fimasartan patient compliance rate of $90 \%$, which is an outstanding result compared to those of the study conducted by Wogen et al., who compared amlodipine, lisinopril, and valsartan in participants in a similar age group [31]. It was found that a higher compliance rate resulted in a larger decrease in BP. When persistence was established (when $95 \%$ of the population was continuously given the medication), fimasartan was found to be superior to the $70-80 \%$ rate at 2 months reported in another study [31]. According to a study that 
explored ACEIs and compliance rates for ARBs, the compliance rates of conventional ACEIs and ARBs were approximately $88 \%$ [32]. In general, it is known that drug compliance is directly associated with a decrease in BP and a decrease in the incidence of cardiovascular events. The overall compliance with treatment with fimasartan in this study was extremely high, and the lowest compliance rate out of the four compliance rates accounted for only $1.7 \%$ of the overall population. Furthermore, similar to the previous studies, decreases in the DBP and SBP values in this study were found to be larger when compliance was better. Therefore, the results indicate that fimasartan increases the compliance of patients with the treatment and improves the rate at which BP is controlled because it has powerful antihypertensive properties and minimal adverse reactions.

\subsection{Limitations}

There were a few limitations in this study. First, it is not certain whether the results can be generalized and applied to other ethnic groups, as this trial was performed only by primary-care physicians in Korea. However, similar results can be expected in other ethnic groups, considering that the research on ARBs conducted in Western countries identified effects analogous to those in Korea and Asia [6]. Second, the accuracy of the study results may be questioned because this was a post-marketing observational study that did not have established inclusion or exclusion guidelines and was an open-label, observational study that relied on doctors' decisions for patient inclusion. However, this type of study design enabled the inclusion of a more diverse participating population and reflected the actual clinical situation more accurately and realistically. Third, the study was not able to verify whether the patients actually took the medication, as the study only depended on an analysis of patients' recall. However, previous validation studies have found good correlations between prescription claims and actual drug use [33], and this study found that the rate of drug consumption correlated well with patients' verbal responses. Therefore, it is believed that there should not be a large discrepancy between prescription claims and actual drug use in this study.

\section{Conclusion}

Fimasartan, the ninth ARB to be developed, has minimal side effects, high overall patient compliance, and an evident effect on decreasing BP. Accordingly, we believe that fimasartan can be used safely because its effectiveness and side effects did not differ significantly according to sex, age, and concomitant disease.
Acknowledgments We sincerely thank the clinical research nurse Min Young Kim for managing the data and professor Dae Ryong Kang for assisting with statistics. This study was funded by Boryung Pharmaceutical Company, Korea. Please see Online Resource for the full contributors' list.

Open Access This article is distributed under the terms of the Creative Commons Attribution Noncommercial License which permits any noncommercial use, distribution, and reproduction in any medium, provided the original author(s) and the source are credited.

\section{References}

1. Wassmann S, Nickenig G. The role of the AT1 receptor in the cardiovascular continuum. Eur Heart J. 2004;6(Suppl H):H3-9.

2. Aulakh GK, Sodhi RK, Singh M. An update on non-peptide angiotensin receptor antagonists and related RAAS modulators. Life Sci. 2007;81(8):615-39.

3. Gavras H, Flessas A, Ryan TJ, et al. Angiotensin II inhibition: treatment of congestive cardiac failure in a high-renin hypertension. JAMA. 1977;238:880-92.

4. Choi DJ, Han S, Jeon ES, et al. Characteristics, outcomes and predictors of long-term mortality for patients hospitalized for acute heart failure: a report from the Korean heart failure registry. Korean Circ J. 2011;41(7):363-71.

5. Sawada T, Yamada H, Dahlöf B, et al. on Kyoto Heart Study Group. Effects of valsartan on morbidity and mortality in uncontrolled hypertensive patients with high cardiovascular risks: Kyoto Heart Study. Eur Heart J. 2009;30(20):2461-9.

6. Mochizuki S, Dahlöf B, Shimizu M, et al. on Jikei Heart Study Group. Valsartan in a Japanese population with hypertension and other cardiovascular disease (Jikei Heart Study): a randomised, open-label, blinded endpoint morbidity-mortality study. Lancet. 2007;369(9571):1431-9.

7. Mancia G, De Backer G, Dominiczak A, et al. Guidelines for the management of arterial hypertension: the task force for the management of arterial hypertension of the European Society of Hypertension (ESH) and of the European Society of Cardiology (ESC). J Hypertens. 2007;25:1105-87.

8. Ogihara T, Kikuchi K, Matsuoka H, et al. Japanese Society of Hypertension committee. The Japanese society of hypertension guidelines for the management of hypertension (JSH 2009). Hypertens Res. 2009;32(1):3-107.

9. The Seventh Report of Joint National Committee on prevention, detection, evaluation, and treatment of high blood pressure: the JNC 7 report. JAMA. 2003;289:2560-72.

10. Wexler RR, Greenlee WJ, Irvin JD, et al. Nonpeptide angiotensin II receptor antagonists: the next generation in antihypertensive therapy. J Med Chem. 1996;39:625-56.

11. Zannad F, Fay R. Blood pressure-lowering efficacy of olmesartan relative to other angiotensin II receptor antagonists: an overview of randomized controlled studies. Fundam Clin Pharmacol. 2007;21(2):181-90.

12. White WB, Weber MA, Sica D, et al. Effects of the angiotensin receptor blocker azilsartan medoxomil versus olmesartan and valsartan on ambulatory and clinic blood pressure in patients with stages 1 and 2 hypertension. Hypertension. 2011;57(3):413-20.

13. Nagel JM, Tietz AB, Göke B, et al. The effect of telmisartan on glucose and lipid metabolism in nondiabetic, insulin-resistant subjects. Metabolism. 2006;55(9):1149-54.

14. Sica DA, Schoolwerth AC. Part 1. Uric acid and losartan. Curr Opin Nephrol Hypertens. 2002;11(5):475-82. 
15. Yi S, Kim TE, Yoon SH, et al. Pharmacokinetic interaction of fimasartan, a new angiotensin II receptor antagonist, with amlodipine in healthy volunteers. J Cardiovasc Pharmacol. 2011;57:682-9.

16. Kim TW, Yoo BW, Lee JK, Kim JH, Lee KT, Chi YH, Lee JY. Synthesis and antihypertensive activity of pyrimidin-4(3H)-one derivatives as losartan analogue for new angiotensin II receptor type 1 (AT1) antagonists. Bioorg Med Chem Lett. 2012;22(4): 1649-54.

17. Lee SE, Kim YJ, Lee HY, et al. Efficacy and tolerability of fimasartan, a new angiotensin receptor blocker, compared with losartan (50/100 mg): A 12-week, Phase III, multicenter, prospective, randomized, double-blind, parallel-group, dose escalation clinical trial with an optional 12-week extension phase in adult Korean patients with mild-to-moderate hypertension. Clin Ther. 2012;34(3):552-68.

18. Basile J. Blood pressure responder rates versus goal rates: which metric matters? Ther Adv Cardiovasc Dis. 2009;3(2):157-74.

19. Yusuf S, Teo K, Anderson C, on Telmisartan Randomised AssessmeNt Study in ACE iNtolerant subjects with cardiovascular Disease (TRANSCEND) Investigators, et al. Effects of the angiotensin-receptor blocker telmisartan on cardiovascular events in high-risk patients intolerant to angiotensin-converting enzyme inhibitors: a randomized controlled trial. Lancet. 2008;372: 1174-83.

20. McIntyre M, Coffe SE, Michalok RA, et al. Losartan, an orally active angiotensin (AT1) receptor antagonist: a review of its efficacy and safety in essential hypertension. Pharmacol Ther. 1997;74(2):181-94.

21. McClellan JK, Goa KL. Candesartan cilexetil: a review of its use in essential hypertensions. Drugs. 1998;56(5):847-69.

22. Gillis JC, Merkham A. Irbesartan: a review of its pharmacodynamic and pharmacokinetic properties and therapeutic use in the management of hypertension. Drugs. 1997;54(6):885-902.

23. Sica D, White WB, Weber MA, et al. Comparison of the novel angiotensin II receptor blocker azilsartan medoxomil vs valsartan by ambulatory blood pressure monitoring. J Clin Hypertens (Greenwich). 2011;13:467-72.

24. Haymore BR, Yoon J, Mikita CP, et al. Risk of angioedema with angiotensin receptor blockers in patients with prior angioedema associated with angiotensin-converting enzyme inhibitors: a metaanalysis. Ann Allergy Asthma Immunol. 2008;101:495-9.

25. Yusuf S, Teo KK, Pogue J, et al. Telmisartan, ramipril, or both in patients at high risk for vascular events. $\mathrm{N}$ Engl $\mathrm{J}$ Med. 2008;358:1547-59.

26. Sica DA, Black HR. Current concepts of pharmacotherapy in hypertension: ACE inhibitor-related angioedema: can angiotensin-receptor blockers be safely used? J Clin Hypertens (Greenwich). 2002;4:375-80.

27. Oparil S, Williams D, Chrysant SG, et al. Comparative efficacy of olmesartan, losartan, valsartan, and irbesartan in the control of essential hypertension. J Clin Hypertens. 2001;3:283-91.

28. Neutel JM, Smith DHG. Evaluation of angiotensin II receptor blockers for 24-hour blood pressure control: Meta-analysis of a clinical database. J Clin Hypertens. 2003;1:58-63.

29. Center for Drug Evaluation and Research Medical Review(s). NDA: 200796 Azilsartan medoxomil (Edarbi) for hypertension [online]. http://www.accessdata.fda.gov/drugsatfda_docs/nda/ 2011/200796Orig1s000MedR.pdf.

30. Blankestijn PJ, Rupp H. Clinical profile of eprosartan: a different angiotensin II receptor blocker. Cardiovasc Hematol Agents Med Chem. 2008;6(4):253-7.

31. Wogen J, Kreilick CA, Livornese RC, et al. Patient adherence with amlodipine, lisinopril, or valsartan therapy in a usual-care setting. J Manag Care Pharm. 2003;9(5):424-9.

32. Vegter S, Nguyen NH, Visser ST, et al. Compliance, persistence, and switching patterns for ACE inhibitors and ARBs. Am J Manag Care. 2011;17(9):609-16.

33. Enlund $\mathrm{H}$. Measuring patient compliance in antihypertensive therapy-some methodological aspects. J Clin Hosp Pharm. 1982;7(1):43-51. 